The Impact of Health Education on Attitudes of Parents and Religious Leaders towards Female Genital Mutilation

Deldar Morad Abdulah: Certificate: Master in Public Health (Australia); Affiliation: Lecturer, Adult Nursing Department, College of Nursing, University of Duhok, Iraqi Kurdistan, Iraq; Email: deldarmorad@gmail.com; Phone: +9647507443319; Corresponding Author

Angela Dawson: Certificate: $\mathrm{PhD}$ in Public Health (Australia); Affiliation: Professor, The Australian Centre for Public and Population Health Research, Faculty of Health, University of Technology, Sydney, Australia; Email: Angela.Dawson@uts.edu.au; Phone: 0061466819780

Bewar Abdulaziz Sedo: Certificate: Master in Political Sciences (India); Affiliation: Assistant Lecturer, Department of Political Science, College of Humanities, University of Duhok, Iraqi Kurdistan, Iraq; Email: bewareziz@yahoo.com, Phone:+9647500195935

Word count: 3570 words 


\title{
The Impact of Health Education on the Attitudes of Parents and Religious Leaders towards Female Genital Mutilation
}

\begin{abstract}
Background: Previous studies conducted in Iraqi Kurdistan have reported that parent's decisions to circumcise their daughters are is based upon religious or cultural beliefs. Despite the widely-spread practice of female genital mutilation (FGM), the effectiveness of educational strategies to change attitudes towards FGM have not been examined in this region. The present investigation examined the effectiveness of a short-term educational intervention to change the attitudes of parents and religious leaders towards FGM.

Methods: One hundred and ninety-two Mullahs (religious leaders), 212 Mokhtars (traditional leaders), and 523 parents in rural areas in Iraqi Kurdistan were invited in a pre and posttest community-based interventional study in 2017. The Health Belief Model informed the intervention and participants' attitudes were compared across two stages of the study.

Results: The attitudes of Mullahs, Mokhtars, and parents substantially changed from a position of supporting female circumcision to expressing a wish to abandon the practice and not cut their future daughters (OR: 1.57 (95\% CI: 1.02-2.42, 1.99 (95\% CI: 1.3-3.04, and 0.13 (95\% CI: $0.09-0.18$, respectively).

Conclusions: The present study suggests that short education interventions can be an effective strategy to change the attitudes of parents and public leaders towards FGM. Health education is a useful strategy to changes attitudes. However, such interventions must delivered alongside others to ensure a multifaceted approach to addressing the complex social dynamics. A comprehensive public health approach is therefore necessary that includes legal measures, community based action and an appropriate health system approach
\end{abstract}

Keywords: education; female genital mutilation; parents

\section{Key Messages}

- Short educational interventions can be an effective strategy to change the attitudes of parents and public leaders towards FGM.

- Men must be involved in health education interventions to changes attitudes towards FGM.

- Increasing social marketing efforts may be useful to improve knowledge of the legal status of FGM alongside other educational efforts. 
- A coordinated holistic approach to preventing FGM and evaluating it effectiveness is needed.

\section{Introduction}

The World Health Organization (WHO) defines female genital mutilation (FGM) as the total or partial removal of the external female genitalia, or procedures such as pricking, scarring or burning for non-therapeutic purposes. The high prevalence of FGM in Iraqi Kurdistan has been a concern of the Kurdistan Regional Government, health organizations, and non-governmental organizations (NGOs) for the last decade. ${ }^{1}$

FGM is undertaken on girls as young as two months and has been described as a violence against women and girls that denies their human rights. ${ }^{1}$ FGM is a global issue. It is practiced in Africa, Asia and the Middle East ${ }^{2}$ as well as by migrants from these regions to high-income countries where FGM is not traditionally practiced. $\frac{3}{-}$ According to WHO, FGM affects 100 to 140 million women worldwide, and 3 million girls are at a risk each year. ${ }^{4}$

FGM is associated with adverse health consequences depending on the type and the conditions in which it is undertaken. $\frac{5}{}$ Health consequences include chronic pain, urination difficulties, recurrent urinary tract infections, obstetric complications, sexual and psychological problems and death resulting from hemorrhage.,$\underline{5}$

Iraqi Kurdistan is a federal region inside Iraq with a population of more than four million people, with the majority of Kurdish ethnicity. In this region, Islam is the main religion followed by minority ethnic and religious groups such as Turkmens, Arab, Yazidis, and Christian populations. ${ }^{7}$

Local non-governmental organizations, women's activists, and international human rights organizations have raised concerns about the high prevalence of FGM in Iraqi Kurdistan for more than a decade. In response, The Ministry of Health has conducted public awarenessraising activities.

The self-reported and clinical prevalence rates of FGM in Erbil city among women aged 15-49 years old have been reported by Yasin and Al-Tawil et al $^{6}$ at $73.3 \%$, and 58.6\%, respectively. A lower overall prevalence rate of $23 \%$ was reported among females aged 6 months to 20 years old by Saleem and Othman et al ${ }^{7}$, in three provinces of Iraqi Kurdistan. WADI, the Association for Crisis Assistance and Development Cooperation, a German NGO, has reported an overall prevalence of $38.2 \%$ among females aged 14 and older in the Kirkuk Governorate. ${ }^{8}$ 
The Kurdistan Parliament passed the Family Violence Law, criminalising FGM in 2011, but NGOs report the continuation of the practice, especially in rural locations. ${ }^{-}$The UN Assistance Mission in Iraq (UNAMI) undertook a survey of 5,990 mothers of girls aged 4 to 14 years in partnership with the Kurdistan Regional Government (KRG), High Council of Women Affairs, the KRG Ministry of Planning, and UNICEF during 2015-2016 and reported a prevalence of $44.5 \% . \underline{10}$

The 2016 UNAMI report identified girls and women to be at a high level of risk of exposure to violence and discrimination including physical abuse, honor-based killings, FGM, selfimmolation, and sexual violence and harassment. The report calls upon local authorities to undertake action to improve the human rights of women and girls and prevent gender-based violence including FGM. $\stackrel{11}{ }$

Previous studies conducted in Iraqi Kurdistan have reported cultural and/or religious reasons as the main drivers for the continuation of FGM $\stackrel{8,7,6}{ }$, therefore, parents, religious leaders, and villages Mokhtars are likely to play a key role in the abandonment of the practice.

There is no research is concerning the effectiveness of strategies to prevent FGM in Iraqi Kurdistan. We undertook exploratory work to evaluate the effectiveness of a short-term education strategy on the attitudes of Mullahs, Mokhtars, and parents towards FGM in rural areas of three governorates in Iraqi Kurdistan. We expected the positive attitudes of the participants towards the FGM practice to decrease in the post-intervention stage following educational sessions compared to the pre-intervention stage.

The purpose of this study was to evaluate the effectiveness of a short-term education strategy on the attitudes of Mullahs (religious leaders in Islam), Mokhtars (traditional leaders in the Kurdish culture), and parents (mothers or fathers of married or single females of undetermined FGM status) towards the practice of FGM in rural areas of three governorates in Iraqi Kurdistan.

\section{Methods}

\section{Study Design and Sampling}


The parents; either mother or father; of married or single females (undetermined FGM status), Mullah and Mokhtar of villages were invited to partake in a pre and post-test interventional study. The participants regardless of their age and other socio-demographic factors participated in three sessions of an FGM education intervention underpinned by the Health Belief Model (HBM) between February 19, 2017, and July 31, 2017. Those who did not wish to participate, or did not attend at least two sessions of the education project were excluded from the study. Only Muslims were included in this study, as Christians and Yazidis in Iraqi Kurdistan do not practice FGM in accordance with previous research. ${ }^{7}$

The sampling was undertaken in two steps. First, a list of all residential villages in Iraqi Kurdistan, including Duhok, Erbil, and Raparin (a semi-autonomous province) were provided by the Provincial governments, consecutively numbered and entered into the statistical software package SPSS. Of the total number of 3680 villages across the three provinces, a random sample of 220 Muslim villages was identified for recruitment into the study by generating a list of simple random numbers using SPSS. All Mullahs and Mokhtars of the selected villages were invited to take part in the study. All villages included in the study had has a maximum one religious leader and each village has one traditional leader.

Of the 202 mullahs, four of the mullahs did not accept the invitation to participate and six of them could not be reached at the time of the study (response rate: 95.0\%). One hundred and ninety-two mullahs were recruited for the study. Of the total 220 Mokhtars, three did not accept the invitation to participate due to personal issues and five Mokhtars could not be contacted (response rate: 96.3\%). Two hundred and twelve Mokhtars were recruited in the study.

Of the total 220 villages randomly selected for the study, the eligible parents in households were invited to participated in the sessions. At this step, 574 parents were included in the study through convenience sampling. A simple random sample of 574 parents was selected from the identified villages in the sampling second step generated by a computer.

Of the 574 parents, 27 did not participate due to family and work commitments. Of the remaining 547 parents, eight participants did not attend the sessions, 13 were lost-to-follow-up and three parents did not attend all sessions (response rate: 91.1\%). Lastly, 523 parents, including 167 in Duhok, 232 in Erbil, and 124 in Raparin provinces were included in the study (as shown in the flowchart-Figure 1).

\section{Educational Intervention}


The first author, a public health professional in partnership with medical staff developed the education course according to the four principles of the Health Belief Model. These principles included (1) perceived susceptibility to the adverse effects of FGM as a serious health condition leaving long-term psychological, medical, somatic, and personal issues, (2) perceived seriousness of the consequences of FGM and its long-term complications on the individual and society, (3) perceived benefits of specified actions to abandon FGM, and (4) perceived barriers to take action against FGM in the community. The educational sessions comprised health talks, drawing, and photographs, leaflets, films in the local language, a social media page, and discussion sessions. The first author, three general practitioners, five nurses, and community workers delivered the education program in the local language in Duhok.

The authors of the study were unable to deliver the education program to the participants in three selected provinces; therefore, the investigators trained a team. Two consecutive meetings about the curriculum and delivery mode were organized by the authors prior the study to ensure the education sessions were delivered in the same manner in all sites. The Health Belief Model underpinning the intervention was explained to the team of research assistants who were also training to deliver the questionnaire in Erbil and Raparin. The two teams comprised four general practitioners, eight nurses, and eleven social workers.

The three, four-hour education sessions were provided to the participants at the Mokhtar's home in each village within a one-week period with a one-day interval between the sessions. The attitudes of the participants were assessed before the start of the program on the first day and four weeks after the final session of the intervention.

\section{Measurement Criteria}

Data were collected from the participants using an interviewer-administered questionnaire in the local language that was adapted from survey tools used in previous studies in the region. $\underline{12}$, 7, $\underline{6}$ An interviewer administered the questionnaire to individuals at Mokhtar home individually. Participants were asked if they had received formal education (yes or no), if they knew if FGM was legal (yes or no), if they agreed with ending the practice (yes or no), if they agreed with supporting FGM abandonment efforts (yes or no), and their readiness to ask people to stop FGM (yes or no). The same questionnaire was delivered pre and posttest.

\section{Patient and Public Involvement Statement:}

No patients were involved in this study.

\section{Statistical Methods}


The study data were analyzed using the Statistical Package for Social Sciences (version 23:00 IBM). McNemar's statistical test was used to establish the effectiveness of the education program. Predictors of support for the abandonment of FGM for parents, Mullahs, and Mokhtars were examined using a binary regression model. The level of less than 0.05 was considered as statistically significant level. The total sample size required was estimated using software $\mathrm{G}^{*}$ Power 3.3.19. Assuming an estimated odds ratio of 3.25 for improvement in parents attitude, a two tailed p-value, $10 \%$ proportion of discordant pairs with McNemar test, a sample size of 440 people would have power of $95 \%$.

\section{Ethical Considerations}

Ethical clearance was obtained from the Board of Relief and Humanitarian Affairs in the Duhok Governorate, the Organizations Department of the Erbil Governorate and the semiautonomous Raparin administration in 2016. The participants were guaranteed that their personal information would remain confidential. The participants were not informed of the study purposes, but their verbal consent was obtained for the interview and the publication of results.

\section{Results}

The mean age of the parents who participated in the study was 50.18 (SD 22.42) years ranged from 15 to 95, including 378 mothers and 145 fathers. The majority of the parents were not formally educated $(73.4 \%)$ and more than half of them $(50.5 \%)$ were unaware that FGM is illegal in Kurdistan. Of the parents were who were aware of the law in relation to FGM, more than three quarters $(76.8 \%)$ had received the information from the television followed by information provided by the staff of NGOs involved in prevention efforts (17.4\%), as shown in Table 1.

Table 1: Baseline characteristics of the parents of daughters.

\begin{tabular}{lll}
\hline \multicolumn{1}{c}{ Parents' Characteristics $(\mathbf{n}=\mathbf{5 2 3})$} & \multicolumn{3}{c}{$\mathbf{~}$} \\
\cline { 2 - 3 } & \multicolumn{1}{c}{$\mathbf{N}$} & \multicolumn{1}{c}{$\%$} \\
\hline Age (year); Mean/S.D. & 50.18 & 22.42 \\
\hline
\end{tabular}




\begin{tabular}{lll}
\hline Parents & & 72.3 \\
Mothers & 378 & 27.7 \\
$\quad$ Fathers & 145 & 26.6 \\
\hline Education Level & & 73.4 \\
$\quad$ Educated & 139 & 49.5 \\
$\quad$ Uneducated & 384 & 50.5 \\
\hline Do you know that female circumcision is now illegal in Kurdistan? & & \\
Yes & 259 & 17.4 \\
No & 264 & 76.8 \\
\hline Source of FGM information & & 2.7 \\
NGO teams & 45 & 0.8 \\
TV & 199 & 2.3 \\
Radio & 7 & 2 \\
Newspaper & 2 & \\
Public & 6 & \\
\hline
\end{tabular}

FGM: female genital mutilation; S.D.: Standard Deviation; F: Frequency

The study revealed that the attitudes of village Mullahs and Mokhtars changed following the educational intervention. Mullah and Mokhtar support for the abandonment of FGM changed from $37.5 \%$ to $72.4 \%$ and from $36.8 \%$ to $77.4 \%$ ( $<<0.0001)$, respectively. Similarly, a greater proportion of leaders were prepared to ask people to stop performing FGM after they had participated in the education program from $38.0 \%$ to $74.0 \%$ for Mullahs and from $38.7 \%$ to $83.4 \%$ for Mokhtars $(\mathrm{p}<0.0001)$, see Table 2 .

Table 2 shows that the percentage of the families who indicated a readiness to continue the practice on their futures daughters was reduced following the intervention. This was significant from $53.2 \%$ to $10.3 \%(\mathrm{p}<0.0001)$. Similarly, the percentage of the parents who indicated a willingness to support a program of the FGM abandonment increased from $35.2 \%$ to $93.7 \%$ following the intervention $(\mathrm{p}<0.0001)$. Similar findings were found for mothers and fathers.

Table 2: Difference in the attitudes of Mullahs, Mokhtars, and parents towards FGM between pre and post the education intervention

Participants' attitudes $\quad$ Baseline $\quad$ Follow-up $\quad$ Test of significance*




\begin{tabular}{|c|c|c|c|}
\hline \multicolumn{4}{|l|}{ Mullahs' Attitudes (n=192) } \\
\hline Do you support the abandonment of FGM? & $72(37.5)$ & $139(72.4)$ & \multirow{2}{*}{$\begin{array}{l}\text { OR: } 1.57 \text { (95\% CI: } 1.02-2.42 \\
\text { OR: } 1.74 \text { (95\% CI: } 1.13-2.69)\end{array}$} \\
\hline Are you ready to ask people in mosque to stop practicing FGM? & $73(38.0)$ & $142(74.0)$ & \\
\hline \multicolumn{4}{|l|}{ Mokhtars' Attitudes (n=212) } \\
\hline Do you support the abandonment of FGM? & $78(36.8)$ & $164(77.4)$ & \multirow{2}{*}{$\begin{array}{l}\text { OR:1.99 (95\% CI: } 1.3-3.04) \\
\text { OR: } 3.19 \text { (95\% CI: } 2.02-5.03)\end{array}$} \\
\hline Are you ready to ask people to stop FGM? & $82(38.7)$ & $177(83.5)$ & \\
\hline \multicolumn{4}{|l|}{ Parents' Attitudes (Total $=523)$} \\
\hline Do you wish for your future daughters to have FGM? & $278(53.2)$ & $54(10.3)$ & \multirow{2}{*}{$\begin{array}{l}\text { OR: } 0.13 \text { (95\% CI: } 0.09-0.18) \\
\text { OR: } 8.06 \text { (95\% CI: } 5.43-11.97)\end{array}$} \\
\hline $\begin{array}{l}\text { Do you think that education about FGM should be provided in } \\
\text { your village? }\end{array}$ & $184(35.2)$ & $490(93.7)$ & \\
\hline \multicolumn{4}{|l|}{ Mothers' attitudes $(n=378)$} \\
\hline Do you wish for your future daughters to have FGM? & $171(45.2)$ & $36(9.5)$ & \multirow{2}{*}{$\begin{array}{l}\text { OR: } 0.09 \text { (95\% CI:0.06-0.13) OR: } 7.24 \\
\text { (95\% CI: 4.7-11.16) }\end{array}$} \\
\hline $\begin{array}{l}\text { Do you think that education about FGM should be provided in } \\
\text { your village? }\end{array}$ & $142(37.6)$ & $349(92.3)$ & \\
\hline \multicolumn{4}{|l|}{ Fathers' attitudes $(n=145)$} \\
\hline Do you wish for your future daughters to have FGM? & $107(73.8)$ & $18(12.4)$ & \multirow{2}{*}{$\begin{array}{l}\text { OR: } 0.4 \text { (95\% CI: } 0.22-0.74) \\
\text { OR: } 14.37 \text { (95\% CI: 5-41.35) }\end{array}$} \\
\hline $\begin{array}{l}\text { Do you think that education about FGM should be provided in } \\
\text { your village? }\end{array}$ & $42(29.0)$ & $141(97.2)$ & \\
\hline
\end{tabular}

The difference in attitudes towards FGM in the three provinces is presented in Table 3. The study found the lowest support for FGM in Duhok (26.9\%) compared to 58.6 in Erbil, and $78.2 \%$ in Raparin.

Table 3: Differece in attitudes of parents towards the FGM between pre and post education program according to province

\begin{tabular}{|c|c|c|c|}
\hline Participants' attitudes $(\mathrm{n}=\mathbf{5 2 3})$ & Baseline & $\begin{array}{l}\text { Follow- } \\
\text { up }\end{array}$ & Test of significance* \\
\hline \multicolumn{4}{|l|}{ Duhok (n=167) } \\
\hline Do you wish for your future daughters to have FGM? & 45 (26.9) & $15(9.0)$ & \\
\hline $\begin{array}{l}\text { Do you think that education about FGM should be provided in } \\
\text { your village }\end{array}$ & $57(34.1)$ & $160(95.8)$ & $\begin{array}{l}\text { OR: } 0.04(95 \% \text { CI } 0.02-0.07) \\
\text { OR: } 11.84 \text { (95\% CI: 5.21-26.94) }\end{array}$ \\
\hline \multicolumn{4}{|l|}{ Erbil $(\mathbf{n}=\mathbf{2 3 2})$} \\
\hline Do you wish for your future daughters to have FGM? & $136(58.6)$ & $19(8.2)$ & OR: 0.12 (95\% CI: $0.07-0.2)$ \\
\hline $\begin{array}{l}\text { Do you think that education about FGM should be provided in } \\
\text { your village }\end{array}$ & $92(39.7)$ & $217(93.5)$ & OR: 9.51 (95\% CI: 5.29-17.08) \\
\hline \multicolumn{4}{|l|}{ Raparin $(n=124)$} \\
\hline Do you wish for your future daughters to have FGM? & $97(78.2)$ & $20(16.1)$ & OR: 0.69 (95\% CI: $0.36-1.31)$ \\
\hline $\begin{array}{l}\text { Do you think that education about FGM should be provided in } \\
\text { your village }\end{array}$ & $35(28.2)$ & $113(91.1)$ & OR: 4.04 (95\% CI: $1.94-8.4)$ \\
\hline
\end{tabular}

The attitudes of mothers and fathers towards FGM were examined in 10-year age categories in Table 4 . The study shows that mothers and father under 44 years were significantly more likely to have changed their attitudes towards FGM and less likely to support the practice. However, older mothers and younger fathers indicated that they still supported FGM.

Table 4: The change in parents' attitudes towardsFGM according to age group between pre and post eduaction intervention

\begin{tabular}{|c|c|c|c|c|c|c|}
\hline \multirow{2}{*}{$\begin{array}{l}\text { Age groups } \\
(\mathrm{n}=523)\end{array}$} & \multicolumn{2}{|c|}{ Mothers } & \multirow[b]{2}{*}{ P-Value } & \multicolumn{2}{|c|}{ Fathers } & \multirow[b]{2}{*}{ P-Value } \\
\hline & Baseline & Follow-Up & & Baseline & Follow-Up & \\
\hline
\end{tabular}




\begin{tabular}{|l|l|l|l|l|l|l|}
\hline $15-24$ years old & $29(60.4)$ & $3(6.3)$ & $<0.0001$ & $16(59.3)$ & $3(11.1)$ & $<0.0001$ \\
$25-34$ years old & $31(54.4)$ & $5(8.8)$ & $<0.0001$ & $27(81.8)$ & $7(21.2)$ & $<0.0001$ \\
$35-44$ years old & $18(32.1)$ & $1(1.8)$ & $<0.0001$ & $14(77.8)$ & $2(11.1)$ & $<0.0001$ \\
$45-54$ years old & $26(47.3)$ & $6(10.9)$ & $<0.0001$ & $10(76.9)$ & $0(0.0)$ & n.a. \\
$55-64$ years old & $18(41.9)$ & $5(11.6)$ & 0.001 & $6(66.7)$ & $0(0.0)$ & n.a. \\
$65-74$ years old & $20(45.5)$ & $6(13.6)$ & 0.001 & $16(80.0)$ & $3(15.0)$ & $<0.0001$ \\
$75-84$ years old & $10(27.0)$ & $6(16.2)$ & 0.424 & $13(76.5)$ & $3(17.6)$ & 0.002 \\
$85-95$ years old & $19(50.0)$ & $4(10.5)$ & $<0.0001$ & $5(62.5)$ & $0(0.0)$ & n.a \\
\hline
\end{tabular}

McNemar test was performed for statistical analyses. *The numbers are in frequency (percentage).

Point: The numbers and percentages of pre and post test shown in this table are positive responses of the parents to the question (a total of 207 and 125 parents responded "yes" to the question for pre and post intervention, respectively. The remaining responded "no" to the item question.

There was no association between parents' education and their intention to have FGM performed on their future daughters in mothers $(\mathrm{p}=0.203)$ and fathers $(\mathrm{P}=0.602)$; see Table 5 .

Table 5: The association of parents' eduaction with their wish for FGM to be performed on their future daughters

\begin{tabular}{|c|c|c|c|}
\hline \multirow{2}{*}{$\begin{array}{l}\text { Do you wish for your futures daughters } \\
\text { to have FGM? (Post-Test) }\end{array}$} & \multicolumn{2}{|c|}{ Education Categories } & \multirow{2}{*}{ OR $(95 \% \mathrm{CI})$} \\
\hline & Educated & Uneducated & \\
\hline Mothers & & & OR: 0.58 (95\% CI: $0.24-1.36)$ \\
\hline Agree & $7(6.5)$ & $29(10.7)$ & \\
\hline Disagree & $101(93.5)$ & $241(89.3)$ & \\
\hline Fathers & & & OR: 0.71 (95\% CI: 0.19-2.62) \\
\hline Agree & $3(9.7)$ & $15(13.2)$ & \\
\hline Disagree & $28(90.3)$ & $99(86.8)$ & \\
\hline
\end{tabular}

The predictors of parental, Mullah, and Mokhtar support for FGM abandonment were examined in binary regression model in Table 6 . The analysis showed that parents who had previously supported the abandonment of FGM were more likely to want to stop practicing FGM (P=0.028). In addition, Mullahs in Raprin significantly supported the abandonment of FGM followed by Duhok and Erbil $(\mathrm{P}=0.010)$. While, Mokhtars in Erbil were more likely to support the abandonment of FGM followed by Duhok and Raparin $(\mathrm{P}=0.028)$ and those Mokhtars who supported the abandonment of FGM ( $\mathrm{P}=0.004)$. 


\begin{tabular}{|c|c|c|c|c|c|c|}
\hline Predictors (Parents) & B & S.E. & Sig. & OR & \multicolumn{2}{|c|}{ 95\% C.I. for OR } \\
\hline Age of parent & -.013 & .012 & .257 & .987 & .965 & 1.010 \\
\hline Interviewees & -.580 & .562 & .303 & .560 & .186 & 1.686 \\
\hline Education categories & -.507 & .668 & .448 & .602 & .163 & 2.230 \\
\hline Governorate* & .202 & .443 & .649 & 1.224 & .514 & 2.914 \\
\hline $\begin{array}{l}\text { Pre-agreement to perform } \\
\text { FGM }\end{array}$ & 1.508 & .684 & .028 & 4.516 & 1.181 & 17.271 \\
\hline Source of information & -.510 & .283 & .072 & .601 & .345 & 1.046 \\
\hline \multicolumn{7}{|c|}{ Dependent variable: Mullahs' readiness to abandon FGM after education } \\
\hline Predictors & B & S.E. & Sig. & OR & \multicolumn{2}{|c|}{ 95\% C.I. for OR } \\
\hline Governorate* & -.569 & .220 & .010 & .566 & .368 & .871 \\
\hline Relation with religion & -.338 & .252 & .180 & .713 & .435 & 1.169 \\
\hline Pre-intervention readiness & .289 & .269 & .281 & 1.336 & .789 & 2.261 \\
\hline \multicolumn{7}{|c|}{ Dependent variable: Mullahs' support to abandon FGM after education } \\
\hline Predictors & B & S.E. & Sig. & OR & \multicolumn{2}{|c|}{ 95\% C.I. for OR } \\
\hline Governorate* & -.362 & .164 & .028 & .696 & .505 & .961 \\
\hline Pre-intervention readiness & -.552 & .190 & .004 & .576 & .397 & .836 \\
\hline \multicolumn{7}{|c|}{$\begin{array}{l}\text { Binary regression model was performed for statistical analysis. OR: Odds Ratio } \\
\text { The bold numbers show the predictors. } \\
\text { * Since there is a significant difference in the practice of FGM in each governorate in this region, we included it as a } \\
\text { predictor in the regression analysis. }\end{array}$} \\
\hline
\end{tabular}

\section{Discussion}

Our study shows that health education can be a useful strategy to change the attitudes of the parents and community leaders towards the practice of FGM. The support of Mullahs and Mokhtars for the abandonment of FGM increased by $35 \%$ and $41 \%(p<0.0001)$, respectively. Moreover, there was a 36\% increase in the proportion of Mullahs who were prepared to ask people to stop performing FGM after they had participated in the education program and a $45 \%$ increase for Mokhtars $(\mathrm{p}<0.0001)$. The percentage of the families who indicated a readiness to continue the practice on their futures daughters was significantly reduced following the intervention.

Other studies have also identified the effect of health education on FGM attitudes and future intentions. Research by Asekun-Olarinmoye and Amusan ${ }^{13}$ in a rural community in Nigeria reported that of the participants surveyed those who regarded themselves as traditionalists (83.3\%), (comprised of $65.2 \%$ Muslims and $49.4 \%$ Christians) were more likely to voice their intention to excise their future daughters in the pre-intervention stage of the study. However, these proportions were reduced substantially to $20.6 \%$, and $16.7 \%$, for Muslim and Christian parents, respectively, following a ten-day education intervention. Changes in attitudes towards FGM and future intentions as a result of health education were also were noted in a study by Diop and Askew ${ }^{14}$ in Senegal. This study involved a pre and post-test comparison-group to evaluate the community education program on women willingness to abandon FGM in rural 
areas. The research found a substantial decrease in the prevalence of the FGM among girls aged ten years and younger over a week. The program aimed to empower women using a wide range of education and health-promoting activities among 20 villages.

Differences between fathers and mothers' intentions to have FGM performed on their daughters have been noted before the implementation of health education programs for parents. Asekun-Olarinmoye and Amusan ${ }^{13}$ found that men were significantly more willing to continue FGM compared to women in agreement with the present study ( $73.8 \% \mathrm{vs.} 45.2 \%$, respectively). However, in our study the attitudes of both fathers and mothers changed in the post-intervention stage to indicate less support for the continuation of the practice. Never-the-less men need to be included in all health education efforts as they are the major decision makers in traditional communities and may influence whether FGM is performed or not.

It is concerning that more than half of the participants (50.5\%) did not know that the FGM is illegal in Iraqi Kurdistan. The majority of the participants $(76.8 \%)$ indicated that they became aware that FGM was illegal from the television indicating that it is a key source of information. In other studies, radio has been found to be an authoritative source of information on FGM for

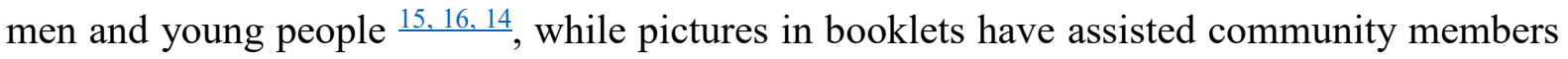
to learn about FGM. $\cdot \underline{17}$

It is interesting to note that our study did not find an association between intention to continue FGM and the education levels of mothers and fathers. This contrasts with other research in

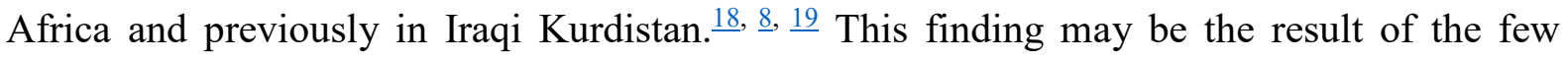
numbers of parents with a college education (No. $=12)$ in our sample.

Although education interventions have been shown to be associated with changes in the intentions of parents or religious leaders to have their daughters excised, attention must also be paid to changing the attitudes of traditional midwives who undertake FGM for a fee. Studies show the importance of providing health education for traditional excisors but also engaging them as educators and change agents to prevent FGM. $\stackrel{13}{20}$ Alternative rites of passage may also be useful where traditional excisors are paid to play a role in ceremonies where no harmful practices are undertaken. $\underline{21}$

While $53.2 \%$ of parents post intervention indicated that they would not have their daughters excised in the future only (38\% of Mullahs and 38.7\% of Mokhtars indicated that they would not continue the practice). This shows a need to scale-up health education for these groups, especially when as leaders they are influential in the decision making of community members 
that may affect the future health status of the girls. Raising female literacy and establishing gender equality are also useful strategies to end harmful practices. (WHO 1999)

\section{Limitations of the study}

This study has some limitations. The results must be interpreted with caution as they are reliant on participant self-reports rather than objective measures. Attitudes were measured on a yes/no basis rather than a scale rendering a less sensitive assessment. However, a scale was not considered feasible due to the low literacy of participants. The findings show the attitudes of participants at two points in times (before and immediately after the intervention) and the effect of the intervention may wear off over time and not affect overall behavioral change. Therefore, continuous observation of the behavior of parents and leaders is required. The mean age of participants at 50 years may reflect stronger support for the practice than a younger sample.

\section{Public health implications}

While we have shown that educational interventions can facilitate positive changes in the attitudes of parents and religious leaders' towards FGM, it is not known if this will translate into sustained behavioral changes. Some studies have shown that the health education programs can raise awareness and change attitudes however on its own health education is insufficient to achieve the complex behavioral change required for the abandonment of FGM. $\underline{22}$.

Population-level interventions such as social marketing campaigns and legislation, as well as community-based activities, school education $\frac{23}{2}$ and health professional training are required. FGM prevention is everybody's business and must involve male and female community members alongside religious and traditional leaders and health professionals. $\underline{24}, \underline{25} \mathrm{~A}$ comprehensive approach is therefore needed to eliminate FGM that is based on a practical framework beyond reproductive health to include "gender education" to address deeply rooted traditions. $\underline{26}$

In 2010, the Human Rights Watch outlined recommendations for a comprehensive public health approach to eliminate FGM. These recommendations included regular data collection, a communications strategy based on public debate both with and within communities, social and medical services for women and girls, protective mechanisms, services to safeguard girls at risk, and active enforcement of the law. In line with these strategies Miller and Moneti et al ${ }^{27}$ suggest six main approaches that can underpin such strategies that are based on lessons learned from the campaign against foot-binding in China. These include the use of 1) non-coercive and non-judgment approaches that focus on human rights and female empowerment; 2) awareness 
raising initiatives for affected populations; 3) bottom up community-based approaches; 4) collective methods to build community commitment to the abandonment of FGM; 5) sustainable diffusion of innovative methods; and 6) the creation of a supportive political environment.

While this study did not provide information about the form of FGM prevention interventions that may be effective in the Iraqi Kurdistan setting it would be useful to trail a number of coordinated approaches to maximize outcomes. For example, social marketing efforts to improve knowledge of the illegal status of FGM could be enhanced by testing various messages using traditional media and scaling these up alongside social media initiatives. Health education delivered by midwives during antenatal visits maybe useful, as well as peer education for new mothers. Traditional midwives could be provided with incentives not to perform FGM and engage families in developing and promoting alternative non-harmful ceremonies.

\section{Conclusions}

Our study suggests that short education interventions can be an effective strategy to change the attitudes of parents and leaders towards FGM. However, such interventions must involve both men and women and be delivered alongside others to ensure a multifaceted approach to address complex social dynamics. A comprehensive public health approach is therefore necessary that includes legal measures, community based action and a health system approach.

\section{Reference List}

1 World Health Organization. A systematic review of the health complications of female genital mutilation including sequelae in childbirth. 2000. 
2 Mahmoud MIH. Effect of female genital mutilation on female sexual function, Alexandria, Egypt. Alexandria Journal of Medicine 2016;52(1):55-9.

3 Abathun AD, Sundby J, Gele AA. Attitude toward female genital mutilation among Somali and Harari people, Eastern Ethiopia. International journal of women's health 2016;8:557.

4 World Health Organization. Eliminating female genital mutilation: the imperative. Switzerland: World Health Organization; 2008.

5 GSN WT, Newsgroup G, Feed G. Female genital mutilation and obstetric outcome: WHO collaborative prospective study in six African countries. Lancet 2006;367(9525):1835-41.

6 Yasin BA, Al-Tawil NG, Shabila NP, et al. Female genital mutilation among Iraqi Kurdish women: a cross-sectional study from Erbil city. BMC public health 2013;13(1):809.

7 Saleem RA, Othman N, Fattah FH, et al. Female genital mutilation in Iraqi Kurdistan: description and associated factors. Women \& health 2013;53(6):537-51.

8 WADI. Female genital mutilation in Iraqi-Kurdistan an empirical study. Association for Crisis Assistance and Development Co-operation; 2010.

9 UNAMI/OHCHR. Report on Human Rights in Iraq January to June 2016. Baghdad, raq; 2016.

10 United States Department of State. Iraq 2016 Human Rights Report. United States Department of State; Bureau of Democracy, Human Rights and Labor; 2017.

11 UNAMI/OHCHR. Report on Human Rights in Iraq July to December 2016. Baghdad, Iraq; 2016.

12 Hussein MA, Adem AA, Mohammed MA. Knowledge, attitude and practice of female genital mutilation among women in Jigjiga Town, Eastern Ethiopia. Gaziantep Medical Journal 2013;19(3):164-8.

13 Asekun-Olarinmoye EO, Amusan OA. The impact of health education on attitudes towards female genital mutilation (FGM) in a rural Nigerian community. The European Journal of Contraception \& Reproductive Health Care 2008;13(3):289-97.

14 Diop NJ, Askew I. The effectiveness of a community-based education program on abandoning female genital mutilation/cutting in Senegal. Studies in Family Planning 2009;40(4):307-18. 
15 Allam M, de Irala-Estevez J, Navajas RF-C, et al. Factors associated with the condoning of female genital mutilation among university students. Public health 2001;115(5):350-5.

16 Babalola S, Brasington A, Agbasimalo A, et al. Impact of a communication programme on female genital cutting in eastern Nigeria. Tropical Medicine \& International Health 2006;11(10):1594-603.

17 Jacoby SD, Lucarelli M, Musse F, et al. A mixed-methods study of immigrant Somali women's health literacy and perinatal experiences in Maine. Journal of midwifery \& women's health 2015;60(5):593-603.

18 Yoder PS, Abderrahim N, Zhuzhuni A. Female genital cutting in the Demographic and Health Surveys: a critical and comparative analysis. 2004.

19 Fund UNCs, Gupta GR. Female genital mutilation/cutting: a statistical overview and exploration of the dynamics of change. Reproductive Health Matters 2013:184-90.

20 Alo OA, Gbadebo B. Intergenerational attitude changes regarding female genital cutting in Nigeria. Journal of Women's Health 2011;20(11):1655-61.

21 Chege JN, Askew I, Liku J. An assessment of the alternative rites approach for encouraging abandonment of female genital mutilation in Kenya: US Agency for International Development; 2001.

22 Feldman-Jacobs C, Ryniak S, Wilcher R, et al. Abandoning female genital mutilation/cutting: an in-depth look at promising practices. 2006.

23 Von der Osten-Sacken T, Uwer T. Is female genital mutilation an Islamic problem? Middle East Quarterly 2007.

24 Abdi M, Askew I. A religious oriented approach to addressing female genital mutilation/cutting among the Somali community of Wajir Kenya. Revised version. 2009.

25 World Health Organization. Female genital mutilation web: World Health Organization; 2016 [Available from: http://www.who.int/mediacentre/factsheets/fs241/en/.

26 World Health Organization. Female genital mutilation: programmes to date: what works and what doesn't: a review. 1999.

27 Miller M, Moneti F, Landini C, et al. Changing a harmful social convention: female genital mutilation/cutting. 2005. 